\title{
[5-(Benzyloxy)-1H-indol-1-yl]acetic acid, an aldose reductase inhibitor and PPARY ligand
}

\author{
Marta Soltesova Prnova', Magdalena Majekova1, Ivana Milackova1, Beatriz Díez-Dacal2, \\ Dolores Pérez-Sala², Muserref Seyma Ceyhan ${ }^{3}$, Sreeparna Banerjee ${ }^{3}$ and Milan Stefek ${ }^{\bowtie}$
}

IInstitute of Experimental Pharmacology and Toxicology, Slovak Academy of Sciences, Bratislava, Slovakia; ${ }^{2}$ Department of Chemical and Physical Biology, Centro de Investigaciones Biológicas, CSIC, Madrid, Spain; 'BDepartment of Biological Sciences, Middle East Technical University,

Ankara, Turkey

Based on overlapping structural requirements for both efficient aldose reductase inhibitors and PPAR ligands, [5-(benzyloxy)-1H-indol-1-yl]acetic acid (compound 1) was assessed for inhibition of aldose reductase and ability to interfere with PPARy. Aldose reductase inhibition by 1 was characterized by IC $C_{50}$ in submicromolar and low micromolar range, for rat and human enzyme, respectively. Selectivity in relation to the closely related rat kidney aldehyde reductase was characterized by approx. factor 50. At organ level in isolated rat lenses, compound 1 significantly inhibited accumulation of sorbitol in a concentration-dependent manner. To identify crucial interactions within the enzyme binding site, molecular docking simulations were performed. Based on luciferase reporter assays, compound 1 was found to act as a ligand for PPARy, yet with rather low activity. On balance, compound 1 is suggested as a promising lead-like scaffold for agents with the potential to interfere with multiple targets in diabetes.

Key words: aldose reductase inhibitor, PPARy ligand, diabetes, indole Received: 05 December, 2014; revised: 21 August, 2015; accepted: 25 August, 2015; available on-line: 08 September, 2015

\section{INTRODUCTION}

Recently, a series of indole based compounds of PPAR agonist activity was disclosed (Mahindroo et al., 2005; 2006a; 2006b; Fig. 1) as the potential anti-diabetic agents. The design of these drugs was based on the general concept stating that most of the known PPAR ligands have an acidic group attached to an aromatic head part, which in turn is attached to an aromatic tail part through a linker. In a very broad sense, this concept matches requirements for aldose reductase inhibitors (ARIs), particularly when considering indole-1-acetic-acid-based PPAR agonists designed by the latter authors shown in Fig. 1.

In this series of novel compounds, the distances between the oxygens in the acidic head and oxygen in

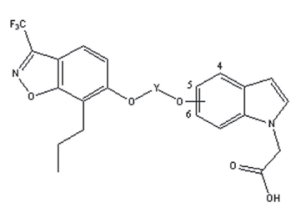

I

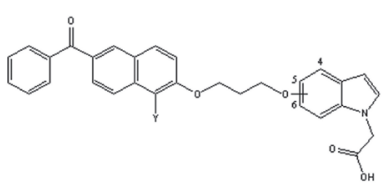

II
Figure 1. Indole-1-acetic-acid-based PPAR agonists (Mahindroo et al., 2005; 2006).

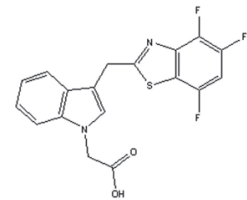

Lidorestat

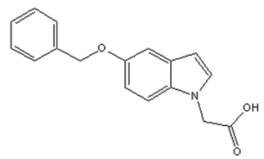

[5-(Benzyloxy)-1H-indol-1-yl] acetic acid (1)
Figure 2. Lidorestat and [5-(benzyloxy)-1H-indol-1-yl] acetic acid (1).

the linker, close to 8-9 $\AA$, were found crucial for high PPAR $\gamma$ agonist activity. The highest activity was recorded for derivatives with hydrophobic tail located in position 5 of the indole core. Shifting the hydrophobic tail to the 4-position decreased the distance between the carboxylic acid and oxygen, decreasing correspondingly the PPAR $\gamma$ agonist activity. Moving the hydrophobic tail to the 6-position further decreased the distance and the activity.

Aldose reductase (ALR2, E.C.1.1.1.21), the first enzyme of the polyol pathway, has been extensively studied as a potential therapeutic target for treatment of chronic diabetic complications (Hotta, 1995; Yabe-Nashimura, 1998; Costantino et al., 2000; Miyamoto, 2002; Srivastava et al., 2005; Alexiou et al., 2009; Tang et al., 2012; Chatzopoulou et al. 2012). Great effort has been devoted to the development of highly efficient, selective and pharmacologically acceptable inhibitors of aldose reductase.

Substituted indole-1-acetic acids, structurally related to the above mentioned indole-based PPAR agonists, represent a group of ARIs of high activity and selectivity (Van Zandt et al., 2005; 2009; Luker et al., 2011; Juskova et al., 2011), with lidorestat as a lead. Yet lidorestat (Fig. 2) was withdrawn from clinical studies owing to its side effects.

A benzyloxy substituted indole-1-acetic acid derivative (compound 1, Fig. 2) was recently included into the study of novel PPAR gamma ligands (daSilva et al. 2013). The docked conformation of 1 revealed favorable polar interactions between the acidic carboxylate group and the polar arm of the binding pocket in the PPAR $\gamma$ active site. Yet the experimental data based on fluorescence thermal shift assay and displacement of fluormone did

e-mail: Milan.Stefek@savba.sk

Abbreviations: AKR1A1, human recombinant aldehyde reductase; AKR1B1, human recombinant aldose reductase; ALR1, aldehyde reductase $A L R 2$, aldose reductase; $A R I$, aldose reductase inhibitor; $D$, distribution ratio; DMSO, dimethyl sulfoxide; FBS, fetal bovine serum; PPARy, peroxisome proliferator-activated receptor gamma 
not allow a clear definition of 1 as binder or nonbinder, basically owing to intrinsic spectral activity interference of the compound.

In this study compound $\mathbf{1}$ is reported as an efficient aldose reductase inhibitor of high selectivity and as a ligand of PPAR $\gamma$. Based on the results, compound 1 is suggested as a promising scaffold for agents with the potential to interfere with multiple targets in diabetes.

\section{MATERIALS AND METHODS}

Chemicals. Compound 1 [5-(Benzyloxy)-1H-indol-1yl]acetic acid (Cat\# 65087) was obtained from MATRIX SCIENTIFIC Columbia, SC, USA. Recombinant human aldose reductase AKR1B1 with more than 95\% purity was from Acris Antibodies, Inc. (San Diego, CA, USA). Sorbitol dehydrogenase, diaphorase, $\beta$-NAD, resazurin, M-199 medium (M 3769), D,L-glyceraldehyde, sodium glucuronate, NADPH, D-glucose, $\beta$-mercaptoethanol and $\mathrm{HClO}_{4}$ were obtained from Sigma-Aldrich (St. Louis, MO). Diethylaminoethyl cellulose DEAE DE 52 was from Whatman International Ltd. (Maidstone, England). The Luciferase Reporter Gene Assay kit was purchased from Roche (Mannheim, Germany). Other chemicals were purchased from local commercial sources and were of analytical grade quality.

Animals. Male Wistar rats, 8-9 weeks old, weighing 200-250 g, were used as organ donors. The animals came from the Breeding Facility of the Institute of Experimental Pharmacology, Dobra Voda (Slovak Republic). The study was approved by the Ethics Committee of the Institute and performed in accordance with the Principles of Laboratory Animal Care $\mathrm{NIH}$ publication 83-25, revised 1985) and the Slovak law regulating animal experiments (Decree 289, Part 139, July 9th 2003).

Cell culture. HCT-116 cells were obtained from the German Collection of Microorganisms and Cell Cultures (DSMZ, Braunschweig, Germany) and cultured in RPMI-1640 medium in 10\% FBS in a humidified atmosphere containing $5 \% \mathrm{CO}_{2}$ at $37^{\circ} \mathrm{C}$. Cell culture media were supplemented with $1 \%$ penicillin/streptomycin. All cell culture media and supplements were purchased from Biochrom (Berlin, Germany).

Preparation of ALR2. ALR2 from rat lens was partially purified using a procedure adapted from Hayman and Kinoshita (1965) as follows: lenses were quickly removed from rats following euthanasia and homogenized in a glass homogenizer with a teflon pestle in 5 volumes of cold distilled water. The homogenate was centrifuged at $10000 \times g$ at $0-4^{\circ} \mathrm{C}$ for $20 \mathrm{~min}$. The supernatant was precipitated with saturated ammonium sulfate at $40 \%$, $50 \%$ and then at $75 \%$ salt saturation. The supernatant was retained after the first two precipitations. The pellet from the last step, possessing ALR2 activity, was dispersed in $75 \%$ ammonium sulfate and stored in smaller aliquots in liquid nitrogen container.

Preparation of ALR1. ALR1 from rat kidney was partially purified according to the reported procedure of Costantino et al. (1999) as follows: kidneys were quickly removed from rats following euthanasia and homogenized in a knife homogenizer followed by processing in a glass homogenizer with a teflon pestle in 3 volumes of $10 \mathrm{mM}$ sodium phosphate buffer, $\mathrm{pH} \mathrm{7.2,} \mathrm{contain-}$ ing $0.25 \mathrm{M}$ sucrose, $2.0 \mathrm{mM}$ EDTA dipotassium salt and $2.5 \mathrm{mM} \beta$-mercaptoethanol. The homogenate was centrifuged at $16000 \times g$ at $0-4{ }^{\circ} \mathrm{C}$ for $30 \mathrm{~min}$ and the supernatant was subjected to ammonium sulfate fractional precipitation at $40 \%, 50 \%$ and $75 \%$ salt saturation. The pel- let obtained from the last step, possessing ALR1 activity, was redissolved in $10 \mathrm{mM}$ sodium phosphate buffer, $\mathrm{pH}$ 7.2, containing $2.0 \mathrm{mM}$ EDTA dipotassium salt and 2.0 $\mathrm{mM} \beta$-mercaptoethanol to achieve total protein concentration of approximately $20 \mathrm{mg} / \mathrm{mL}$. DEAE DE 52 resin was added to the solution $(33 \mathrm{mg} / \mathrm{mL})$ and after gentle mixing for $15 \mathrm{~min}$ removed by centrifugation. The supernatant containing ALR1 was then stored in smaller aliquots in liquid nitrogen. No appreciable contamination by ALR2 in ALR1 preparations was detected since no activity in terms of NADPH consumption was observed in the presence of glucose substrate up to $150 \mathrm{mM}$.

ALR1 and ALR2 enzyme assays. ALR1 and ALR2 activities were assayed spectrophotometrically as described before (Stefek et al., 2008) by determining NADPH consumption at $340 \mathrm{~nm}$ and were expressed as decrease of the optical density $(\mathrm{OD}) / \mathrm{s} / \mathrm{mg}$ protein. To determine ALR2 activity, the reaction mixture contained 4.67 mM D,L-glyceraldehyde as a substrate, $0.11 \mathrm{mM}$ NADPH, $0.067 \mathrm{M}$ phosphate buffer, $\mathrm{pH} 6.2$ and $0.05 \mathrm{~mL}$ of the enzyme preparation in a total volume of $1.5 \mathrm{~mL}$. The reference blank contained all the above reagents except the substrate D,L-glyceraldehyde to correct for oxidation of NADPH not associated with reduction of the substrate. The enzyme reaction was initiated by addition of D,L-glyceraldehyde and was monitored for $4 \mathrm{~min}$ after an initial period of $1 \mathrm{~min}$ at $30^{\circ} \mathrm{C}$. ALR1 activity was assayed analogically using $20 \mathrm{mM}$ Dglucuronate as a substrate in the presence of $0.12 \mathrm{mM}$ NADPH in $0.1 \mathrm{M}$ phosphate buffer $\mathrm{pH} 7.2$ at $37^{\circ} \mathrm{C}$. Enzyme activities were adjusted by diluting the enzyme preparations with distilled water so that $0.05 \mathrm{~mL}$ of the preparation gave an average reaction rate for the control sample of $0.020 \pm 0.005$ absorbance units $/ \mathrm{min}$. The effect of compounds on the enzyme activity was determined by including in the reaction mixture each inhibitor at required concentrations dissolved in water or DMSO at $1 \%$ final mixture concentration. The inhibitor at the same concentration was included in the reference blank. $\mathrm{IC}_{50}$ values (the concentration of the inhibitor required to produce $50 \%$ inhibition of the enzyme reaction) were determined both from the least-square analysis of the linear portion of the semi-logarithmic inhibition curves and non-linear regression analysis. Each curve was generated using at least four concentrations of inhibitor causing an inhibition in the range from at least 25 to $75 \%$.

Eye lens sorbitol assay. The animals in light ether anesthesia were killed by exsanguinations of the carotid artery and the eye globes were excised. The lenses were quickly dissected and rinsed with saline. Compounds dissolved in DMSO were added into the tubes containing freshly dissected eye lenses (1 lens per tube) in M-199 medium at $\mathrm{pH} 7.4$, bubbled at $37^{\circ} \mathrm{C}$ with pneumoxid $\left(5 \% \mathrm{CO}_{2}, 95 \% \mathrm{O}_{2}\right)$, to the final concentrations as reported, $30 \mathrm{~min}$ before adding glucose. The final concentration of DMSO in all incubations was $1 \%$. The incubation was initiated by adding glucose to the final concentration of $50 \mathrm{mM}$ and then continued at $37^{\circ} \mathrm{C}$ with occasional (in about 30-min intervals) bubbling the mixture for approximately 30 -s periods with pneumoxid. The incubations were terminated after a $3-\mathrm{h}$ period by cooling the mixtures in an ice bath, followed by washing the lenses three times with ice-cold phosphate buffered saline $(1 \mathrm{~mL})$. The short term cultivations were preferred to avoid substantial permeability changes of the eye lenses. The washed lenses were kept deep-frozen for sorbitol determination which was performed as described before (Stefek et al., 2011). In brief, the frozen lenses were let to melt at the ambient temperature. Then distilled water 
( $0.2 \mathrm{~mL} / 1$ lens) was added. The lenses were disrupted by a glass rod. The rod was washed twice with distilled water $(0.1 \mathrm{~mL})$ and the suspension was ultra-sounded for 5 min. Thereafter, ice cold $\mathrm{HClO}_{4}(9 \%, 0.4 \mathrm{~mL})$ was added and mixed thoroughly. The mixture was ultra-sounded for another $5 \mathrm{~min}$ and then kept on ice for $30 \mathrm{~min}$ to let proteins precipitate. The precipitated protein was spun off $(15 \mathrm{~min}$ at $3000 \mathrm{rpm})$ at $4^{\circ} \mathrm{C}$. The supernatant was neutralized with concentrated $\mathrm{K}_{2} \mathrm{CO}_{3}(4 \mathrm{M})$. The neutralized supernatant was used for determination of concentration of sorbitol by modified enzymatic analysis (Mylari et al., 2003). In brief, sorbitol was oxidized to fructose by sorbitol dehydrogenase (SDH) with concomitant reduction of resazurin by diaphorase to the highly fluorescent resorufin. The final concentrations of the assay solutions were: diaphorase $(11.5 \mathrm{U} / 25 \mathrm{~mL}$ triethanolamine buffer), $\mathrm{NAD}^{+}(25 \mathrm{mg} / 25 \mathrm{~mL}$ triethanolamine buffer), resazurin $(0.025 \mathrm{~mL} 2 \mathrm{mM}$ resazurin solution in $25 \mathrm{~mL}$ of triethanolamine buffer), SDH (15.025 U/1 mL triethanolamine buffer). Reaction mixtures were incubated for $60 \mathrm{~min}$ at room temperature with an opaque cover. The sample fluorescence was determined at excitation 544 $\mathrm{nm}$, emission $590 \mathrm{~nm}$. After the appropriate blanks were subtracted from each sample, the amount of sorbitol in nmol per gram of lens wet weight in each sample was determined by comparison with a linear regression of sorbitol standards.

Luciferase reporter assay. To determine whether compound 1 acts as a ligand for PPAR gamma, the PPAR $\gamma 1-L B D-G A L 4 D B D$ and $U_{A} G_{S}-4 x T K-L U C$ constructs were used. The UASG-4xTK-Luc construct contains the upstream activating sequence (UAS) of GAL4 upstream of a thymidine kinase (TK) driven luciferase reporter gene (Forman et al., 1995). In the presence of a ligand, the PPAR $\gamma 1 \mathrm{LBD}-\mathrm{GAL}$ 4DBD binds to the UASG-4xTK-Luc reporter gene, driving thereby the transcription of the luciferase gene. HCT-116 cells $\left(2.5 \times 10^{5}\right.$ cells/well $)$ were seeded in 12 -well plates. After $24 \mathrm{~h}$, the cells were transfected with the PPAR $\gamma 1-\mathrm{LBD}$ GAL4DBD (200 ng), UAG ${ }_{\mathrm{s}}-4 \mathrm{xTK}-\mathrm{LUC}(600 \mathrm{ng})$ and $\beta$-GAL (500 ng) constructs, simultaneously. After $6 \mathrm{~h}$ of transfection, the cells were treated with $10 \mu \mathrm{M}, 50 \mu \mathrm{M}$ and $100 \mu \mathrm{M}$ compound 1 for $24 \mathrm{~h}$ in serum free RPMI medium. Luciferase activity was determined by Luciferase Reporter Gene Assay according to the manufacturer's instructions (Roche) and measured with a Modulus luminometer (Turner Biosystems, CA). Normalization of the transfection effciency was carried out by determining $\beta$-galactosidase activity. Results were expressed as fold changes and each assay was carried out independently 3 times with 3 technical replicates.

Computational methods. Input geometries of the compounds studied were obtained by equilibrium conformer systematic search (MMFF94) performed in the program SPARTAN'08 (Wavefunction Inc., USA; Shao et al., 2006). For modeling the enzyme-ligand interaction, the PDB structure of aldose reductase complexed with $\mathrm{NADP}^{+}$and lidorestat was taken from Protein Data Bank (http://www.rcsb.org, structure 1z3n, representing the aldo-keto reductase class AKR1B1). The structure of the enzyme was treated to correct the bonds and hydrogens by means of the software Yasara (Krieger et al., 2002). First, the individual ligand 1 was immersed in original (unoptimized) complex instead of lidorestat and docking procedure according to the local docking protocol of YASARA (with 250 runs and RMSDmin $=5.0 \AA$ ) was performed. The first ten clusters were then searched for the minimum value of $\mathrm{E}_{\text {bin }}$ within the optimization protocol em_run.mcr. An analogous protocol was used for modeling the interaction of compound 1 with ALR1, but in this instance with the pdb structure $3 \mathrm{fx} 4$ (aldoketo reductase AKR1A1 complexed with $\mathrm{NADP}^{+}$and [(5Z)-5-\{[3-(carboxymethoxy)-4-methoxyphenyl]methylidene $\}$ - 2,4-dioxo-1,3-thiazolidin-3-yl]acetic acid ).

Partitioning. The distribution ratios D in 1-octanol/ buffer systems, defined by total concentration of a solute in organic phase divided by that in aqueous phase, were measured using the shake-flask technique (Sangster, 1997) at room temperature. The organic and aqueous phases were mutually saturated. Compound 1 was dissolved in aqueous buffer solution $(0.1 \mathrm{M}$ phosphate buffer $\mathrm{pH}$ 7.4) in final concentration of $100 \mu \mathrm{M}$; the solutions were shaken with 1 -octanol for $3 \mathrm{~h}$. Both aqueous and organic phase volumes were $3 \mathrm{~mL}$. The phases were separated by centrifugation for $1 \mathrm{~h}$. The organic layer was removed with a Pasteur pipette. The concentration of the solute was determined in both phases by UV spectrophotometry.

\section{RESULTS}

Compound 1 was evaluated for its ability to inhibit the in vitro reduction of $\mathrm{D}, \mathrm{L}-\mathrm{glyceraldehyde}$ by partially purified ALR2 from rat lens and human enzyme AKR1B1 using epalrestat as reference. As shown in Table 1, inhibition activity in submicromolar range was recorded for the rat enzyme. For human AKR1B1, inhibition efficacy in low micromolar region was observed.

In testing for selectivity, the comparison to an enzyme with the highest homology, aldehyde reductase (ALR1), was used. The $\mathrm{IC}_{50}$ value of compound 1 for its inhibition of the reduction of glucuronide substrate by partially purified ALR1 from rat kidney, in comparison with the standard valproate, is shown in Table 1.

In the next step, we analyzed the enzyme kinetics for compound 1. Uncompetitive inhibition was observed in relation to D,L-glyceraldehyde as a substrate (Fig. 3) with the corresponding inhibition constant $K_{\mathrm{i}}(\mathbf{1})=0.6 \pm 0.1 \mu \mathrm{M}$.

As shown in Table 2, increased sorbitol levels were recorded in the isolated lenses incubated with glucose, in comparison with control incubations without glucose, reflecting increased flux of glucose through lens cytosolic ALR2. Similarly did other authors (Terashima et al., 1984) observe a more than 10-fold increase of sorbitol levels in the isolated eye lenses incubated with glucose under comparable conditions $50 \mathrm{mM}$ glucose, $4 \mathrm{~h}$ incubation). Sorbitol accumulation was significantly inhibited by compound 1 , present in the incubation medium at a concentration as low as $10 \mu \mathrm{M}$.

Molecular docking studies were carried out to explore the binding pattern and selectivity of inhibition of ALR2 by 1 . As indicated in Fig. 4, the carboxylate anion of 1

Table 1. Inhibitory effect of compound 1 on aldo-keto reductases in comparison with reference epalrestat and valproate

\begin{tabular}{llll}
\hline \multirow{2}{*}{ Compound } & \multicolumn{1}{l}{$\mathrm{IC}_{50}(\mu \mathrm{M})$} & \\
\cline { 2 - 4 } & Rat lens ALR2 & AKR1B1 & Rat kidney ALR1 \\
\hline 1 & $0.73 \pm 0.07$ & $5.40 \pm 1.42$ & $36.82 \pm 2.81$ \\
\hline Epalrestat & 0.25 & n.d. & n.d. \\
\hline Valproate & n.d. & n.d. & $56.1 \pm 2.7$ \\
\hline
\end{tabular}

Results are mean values from two measurements or mean values $\pm \mathrm{SD}$ from at least three measurements. n.d. not determined. 


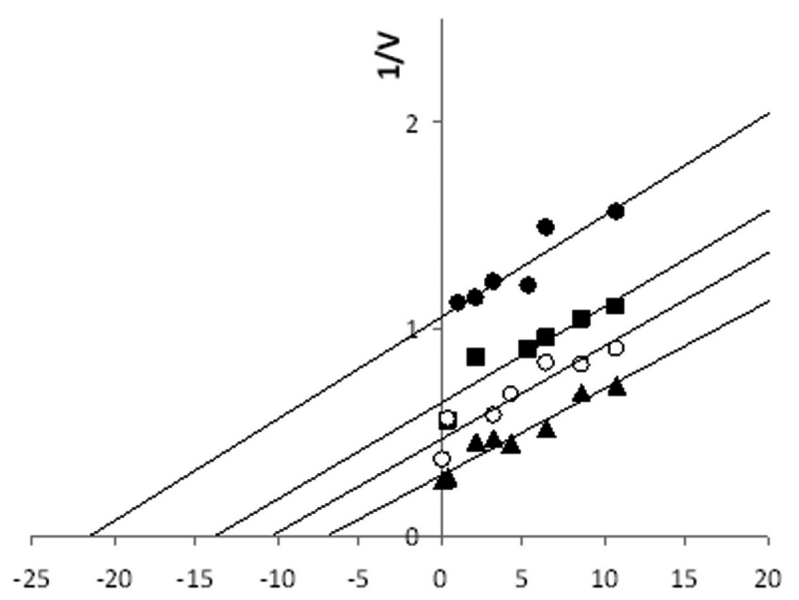

Figure 3. Inhibitory effect of compound 1 on rat lens aldose reductase. Typical double reciprocal plot of the initial enzyme velocity versus the concentration of substrate ( $D, L-g l y c e r a l d e h y d e)$ in the presence or absence of 1: ( $\boldsymbol{\Delta})$ no inhibitor; (o) $0.25 \mu \mathrm{M}$ of $\mathbf{1 ;}(\mathbf{\square}) 0.5 \mu \mathrm{M}$ of $\mathbf{1}(\bullet) 1 \mu \mathrm{M}$ of $\mathbf{1}$ (uncompetitive type of inhibition).

Table 2. Effect of compound 1 in comparison with epalrestat on sorbitol accumulation in isolated rat lenses cultivated with high glucose ${ }^{a}$.

\begin{tabular}{lcc}
\hline Incubation & Sorbitol $(\mathrm{nmol} / \mathrm{g})$ & $\mathrm{n}$ \\
\hline - Glucose & $233.99 \pm 7.80^{\mathrm{b}}$ & 15 \\
\hline + Glucose & $772.90 \pm 19.70$ & 17 \\
\hline + Glucose + 1 (10 $\mu \mathrm{M})$ & $553.08 \pm 38.67 \mathrm{~b}$ & 3 \\
\hline + Glucose + 1 (100 $\mu \mathrm{M})$ & $376.03 \pm 77.91^{\mathrm{b}}$ & 4 \\
\hline + Glucose + epalrestat $(10 \mu \mathrm{M})$ & $684.72 \pm 60.36$ & 4 \\
\hline + Glucose + epalrestat $(50 \mu \mathrm{M})$ & $582.24 \pm 25.10^{c}$ & 3 \\
\hline
\end{tabular}

Results are mean values \pm SEM from $n$ independent incubations. a $G$ lucose, $50 \mathrm{mM}$; time of incubation, 3 hours; $37^{\circ} \mathrm{C}$. ${ }^{b} p<0.001$ vs. (+)Glucose (Student's $t$-test); c $p<0.05$ vs. (+)Glucose (Student's $t$-test)

is anchored into the anionic binding site forming hydrogen bonds with Tyr48 (2.7 $\AA)$, and His110 (2.9 and $3.1 \AA)$, and an electrostatic interaction with the positively charged nicotinamide ring of $\mathrm{NADP}^{+}$. Interactions within the specificity pocket are mediated via $\mathrm{H}$-bond with Leu300 (3.5 $\AA$ ) and $\pi-\pi$ interaction with Trp111.

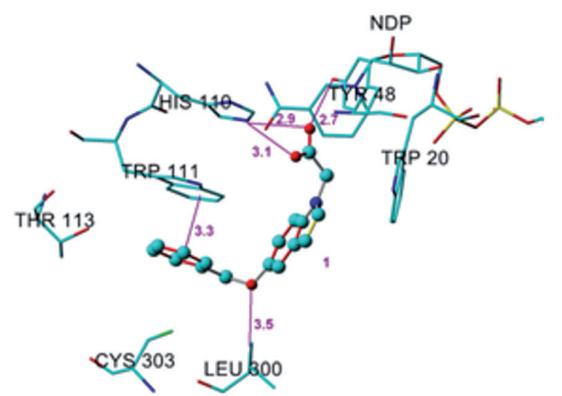

1

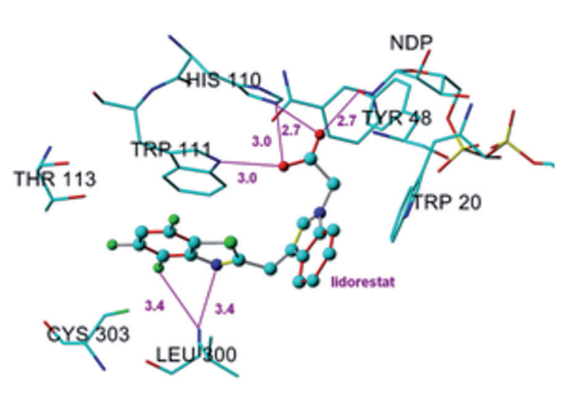

Lidorestat
Figure 4. Identification of key interactions between ALR2 and 1 in comparison with lidorestat.

(H - bonds with Trp111, His110, Tyr48, Leu300 and $\pi-\pi$ interaction with Trp111).
The main interactions of 1 with ALR1, shown in Fig. 5, comprise $\pi-\pi$ interaction with $\operatorname{Trp} 22(3.8 \AA)$ from anionic binding pocket, H-bond with Trp114 (2.9 $\AA)$ from specificity pocket and hydrophobic interaction with Met302 (3.4 $\AA)$.

To determine whether compound 1 acts as a ligand for PPAR $\gamma$, the PPAR $\gamma 1-L B D-G A L 4 D B D$ and $\mathrm{UAG}_{\mathrm{S}^{-}}$ 4xTK-LUC constructs were transfected into HCT-116 cells as reported in the experimental section. In the presence of $50 \mu \mathrm{M}$ and $100 \mu \mathrm{M}$ concentrations of 1 , the luciferase activity was increased significantly, indicating that at these concentrations compound 1 acted as a ligand for PPAR $\gamma$ (Fig. 6). The rough estimate of $\mathrm{EC}_{50} \geq 47.4 \mu \mathrm{M}$ points to compound 1 as a weak ligand for PPAR $\gamma$.

\section{DISCUSSION}

ALR2 enzyme inhibition activity below $1 \mu \mathrm{M}$ was recorded for 1 . The uncompetitive type of inhibition of ALR2 $\left(K_{\mathrm{i}}=0.6 \pm 0.1 \mu \mathrm{M}\right)$ indicates that the glucose substrate may not compete with the inhibitor for the enzyme. Yet, in the light of the findings on ARIs reported by other authors (Cook et al., 1995), binding of compound 1 within the substrate binding site cannot be excluded. The experimentally obtained $K_{\mathrm{m}}$ value for aldose reductase, $\left(K_{\mathrm{m}}\right)^{\text {Glyceraldehyde }}=0.253 \mathrm{mM}$, was in the range of those determined by other authors for partially purified rat lens ALR2 (DeRuiter et al. 1989; DeRuiter \& Mayfield, 1990; Haraguchi et al. 2003).

An important feature of pharmacologically applicable ARIs is their selectivity of action. The co-inhibition of structurally related physiological oxidoreductases might have unwanted side effects. In testing for selectivity, we used the comparison to an enzyme with the highest homology, i.e. aldehyde reductase (ALR1, Barski et al., 1995; Rees-Milton et al., 1998). The corresponding selectivity factor calculated for 1 as $\mathrm{IC}_{50}{ }^{A L R} 1 / \mathrm{IC}_{50}{ }^{\mathrm{ALR} 2}$ was found to be $\sim 50$, which points to a remarkable selectivity.

Inhibition of sorbitol accumulation in isolated lenses indicates the ready uptake of 1 by the eye lens tissue followed by inhibition of the cytosolic ALR2.

Molecular modeling studies revealed key interactions of 1 with amino acid residues of ALR2 binding site, namely the hydrogen bonds with His110 and Leu300 as well as the $\pi-\pi$ interaction between benzene rings of 1 and Trp111. In comparison with 3-substituted lidorestat, the main differences observed were: i) the mirror reorientation of indole moiety caused by repositioning of bulky aromatic substituents from position 3 for lidorestat to 5 for 1 , ii) the hydrogen bonding of lidorestat with Trp111 was replaced by a more favorable $\pi-\pi$ interaction of the benzene ring of 1 with that of Trp111 (Fig. 4).

The specificity pocket of ALR2 is created by residues Trp111, Thr113, Phe122, Ala299 and Leu300 (Howard et al., 2004). The selectivity factor of about 50 determined for compound 1 points to its efficient discrimination between ALR2 and ALR1. This may be accounted for by specific interactions within a specificity 


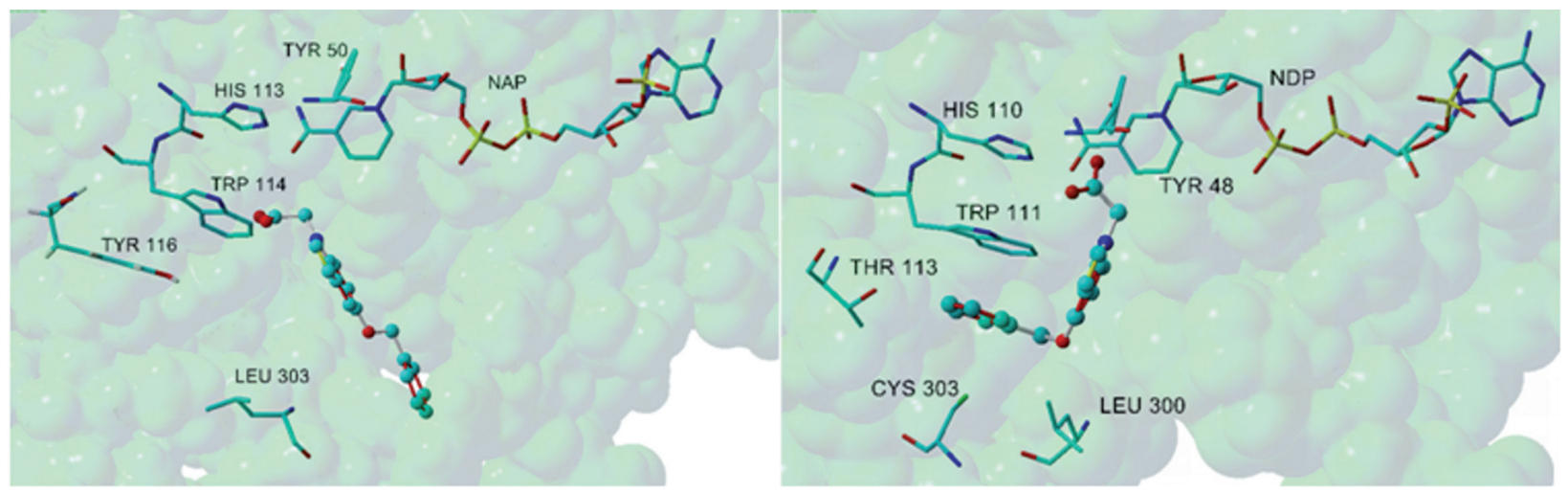

Figure 5. Selective interactions between ALR1 and 1 (left) and ALR2 and 1 (right).

The section 299-302 in ALR1 forces compound 1 to stay in straight position without hydrogen bonds with Tyr 50, His113, Leu 303 and without $\pi-\pi$ interaction with Trp114.

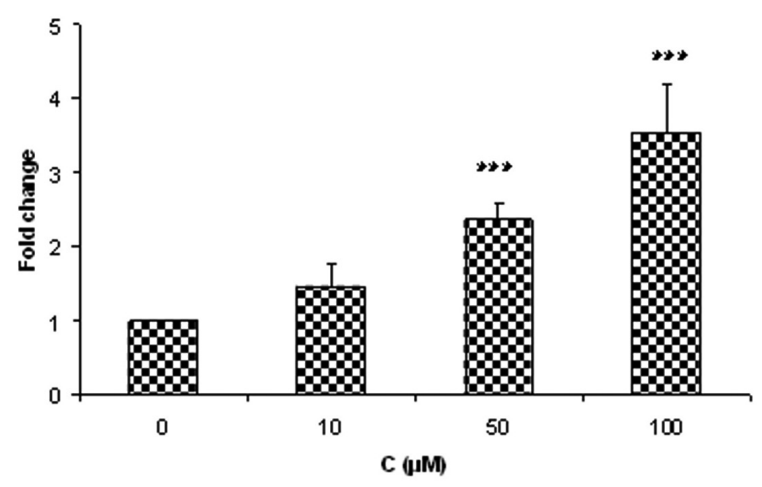

Figure 6. PPARy ligand binding activity of compound 1 as shown by a luciferase reporter gene assay.

Results are mean values \pm SD from at least three independent experiments. ${ }^{* * *} p<0.001$ versus 0 (vehicle control), (One way ANOVA with Dunnett's multiple comparison test).

pocket of ALR2, namely strong hydrogen bond with Leu300, similarly to lidorestat. Moreover, compound 1 is H-bonded also to Cys298 (H-bond length=3.8 $\AA$ ). By docking into the binding site of ALR1, compound 1 was found to adopt a rather straight position without hydrogen bonds with His113, Leu303 and $\pi-\pi$ interaction with Trp111, which is energetically less favorable than the position observed in ALR2. This is caused by sterical restraints of the section 299-302 in ALR1, which has four different residues on comparison with

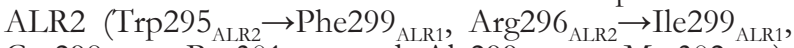
Cys298 $8_{\mathrm{ALR} 2} \rightarrow$ Pro301 $_{\mathrm{ALR} 1}$ and Ala299 ${ }_{\mathrm{ALR} 2} \rightarrow$ Met302 $_{\mathrm{ALR} 1}$ ). As a consequence, in ALR1 binding site, the phenyl ring of $\mathbf{1}$ is not allowed to achieve a favorable $\pi-\pi$ interaction with Trp114 and the whole molecule is moving apart from $\mathrm{NADP}^{+}$, losing thus the interaction with Tyr50, His113 and Leu303 (Fig. 5).

The luciferase reporter assay eliminates the ambiguities in the results of daSilva et al. (2013) caused by potential interference of the intrinsic fluorescence or absorbance with fluormone emission. Our results reveal interference of compound 1 as a ligand with PPAR $\gamma$, yet with a rather weak ligand binding activity.

The optimization process of a lead, applied to improve the affinity and selectivity of a drug candidate, routinely increases lipophilicity and molecular weight. Hence, the general structural requirements for a lead have to be stricter than those used as a measure of druglikeness. So ,the rule of five" has been tightened to the "rule of three" for defining lead-like compounds (Congreve et al., 2003; Verheij, 2006). Accordingly, compound 1 represents a promising lead with $\mathrm{MW}<300$, cLogP in the region from 2.8 to 3.8 , depending on the software used, and a number of hydrogen bond donors 4 . In addition, there is a reasonable water solubility: minimally $1.5 \mathrm{mmol} / \mathrm{L}$. The experimentally determined distribution ratio between water and octanol at $\mathrm{pH} 7.4$ was found to be $0.87\left(\log \mathrm{D}_{7.4}=-0.06002\right)$, which means that under conditions of Vorg=Vaq, the percentage of extraction is as high as $46.5 \%$. This finding, together with sorbitol inhibition in isolated lenses, is a promise of a potentially good bioavailability of 1 under physiologically relevant conditions (Walker \& Testa, 2009).

On balance, therefore, [5-(benzyloxy)-1H-indol-1-yl] acetic acid represents a promising scaffold for efficient and selective inhibitors of aldose reductase with the potential to interact with PPAR $\gamma$ as an additional target in diabetes.

\section{Acknowledgement}

This work was supported by VEGA 2/0041/15, VEGA 2/0033/14, COST action CM 1001 and the joint research project between the Scientific and Technical Research Council of Turkey (TÜBITAK) and the Slovak Academy of Sciences 2013-2015 (project number 113S006) and grant SAF2012-36519 from MINECO (Spain) to DPS.

\section{Declaration of interest}

The authors have declared no conflicts of interest.

\section{REFERENCES}

Alexiou P, Pegklidou K, Chatzopoulou M, Nicolaou I, Demopoulos VJ (2009) Aldose reductase enzyme and its implication to major health problems of the 21(st) century. Curr Med Chem 16: 734-752. doi: $10.2174 / 092986709787458362$.

Barski OA, Gabbay KH, Grimshaw CE, Bohren KM (1995) Mechanism of human aldehyde reductase: characterization of the active site pocket. Biochemistry 34: 11264-11275. Doi: 10.1021/bi00035a036.

Chatzopoulou M, Alexiou P, Kotsampasakou E, Demopoulos VJ (2012) Novel aldose reductase inhibitors: a patent survey (2006-present). Expert Opin Ther Pat 11: 1303-1323. doi: 10.1517/13543776.2012.726615.

Congreve M, Carr R, Murray C, Jhoti H (2003) A 'rule of three' for fragment-based lead discovery? Drug Discovery Today 8: 876-877. doi:10.1016/S1359-6446(03)02831-9.

Cook PN, Ward WHJ, Petrash JM, Mirrlees DJ, Sennitt ChM, Carey F, Preston J, Brittain DR, Tuffin DP, Howe R (1995) Kinetic characteristics of zeneca ZD5522, a potent inhibitor of human and 
bovine lens aldose reductase. Biochem Pharmacol 49: 1043-1049. doi: 10.1016/0006-2952(95)98499-Y.

Costantino L, Rastelli G, Gamberini MC, Barlocco D (2000) Pharmacological approaches to the treatment of diabetic complications. Expert Opin Ther Patents 10: 1245-1262. doi: 10.1517/13543776.10.8.1245.

Costantino L, Rastelli G, Gamberini MC, Vinson JA, Bose P, Iannone A, Staffieri M, Antolini L, Del Corso A, Mura U, Albasini A (1999) 1-Benzopyran-4-one Antioxidants as Aldose Reductase Inhibitors. J Med Chem 42: 1881-1893. doi: 10.1021/jm980441h.

DeRuiter J, Borne RF, Mayfield CA (1989) N- and 2-substituted $\mathrm{N}$-(phenylsulfonyl) glycines as inhibitors of rat lens aldose reductase. J Med Chem 32: 145-151. doi: 10.1021/jm00121a027.

DeRuiter J, Mayfield CA (1990) Inhibitory activity and mechanism of inhibition of the N-[[(4-benzoylamino)phenyl]sulfonyl] amino acid aldose reductase inhibitors. Biochem Pharmacol 40: 2219-2226. doi: 10.1016/0006-2952(90)90715-W.

Forman BM, Tontonoz P, Chen J, Brun RP, Spiegelman BM, Evans RM (1995) 15-Deoxy-delta 12,14-prostaglandin J2 is a ligand for the adipocyte determination factor PPAR gamma. Cell 83: 803-812. doi: 10.1016/0092-8674(95)90193-0.

Haraguchi H, Hayashi R, Ishizu T, Yagi A (2003) A flavone from Manilkara indica as a specific inhibitor against aldose reductase in vitro. Planta Med 69: 853-855. doi: 10.1055/s-2003-43218.

Hayman S, Kinoshita J (1965) Isolation and Properties of Lens Aldose Reductase. I Biol Chem 240: 877-882.

Hotta N (1995) New approaches for treatment in diabetes: Aldose reductase inhibitors. Biomed Pharmacother 49: 232-243. doi: 10.1016/0753-3322(96)82629-1.

Howard EI, Sanishvili R, Cachau RE, Mitschler A, Chevrier B, Barth P, Lamour V, Van Zandt M, Sibley E, Bon C, Moras D, Schneider TR, Joachimiak A, Podjarny A (2004) Ultrahigh resolution drug design I: details of interactions in human aldose reductase-inhibitor complex at 0.66 A. Proteins 55: 792-804. doi:10.1002/prot.20015.

Juskova M, Majekova M, Demopoulos V, Stefek M (2011) Substituted derivatives of indole acetic acid as aldose reductase inhibitors with antioxidant activity: structure-activity relationship. Gen Physiol Biophys 30: 342-349. doi: 10.4149/gpb_2011_04_342.

Krieger E, Koraimann G, Vriend G (2002) Increasing the precision of comparative models with YASARA NOVA - a self-parameterizing force field. Proteins [Online] 47: 393-402. Available at: www.yasara. org. doi:10.1002/prot.10104.

Luker T, Bonnert R, Brough S, Cook AR, Dickinson MR, Dougall I, Logan C, Mohammed RT, Paine S, Sanganee HJ, Sargent C, Schmidt JA, Teague S, Thom S (2011) Substituted indole-1-acetic acids as potent and selective CRTh2 antagonists-discovery of AZD1981. Bioorg Med Chem Lett 21: 6288-6292. doi:10.1016/j. bmcl.2011.08.124.

Mahindroo N, Huang CF, Peng YH, Wang CC, Liao CC, Lien TW, Chittimalla SK, Huang WJ, Chai CH, Prakash E, Chen CP, Hsu TA, Peng CH, Lu IL, Lee LH, Chang YW, Chen WC, Chou YC, Chen CT, Goparaju CM, Chen YS, Lan SJ, Yu MC, Chen X, Chao YS, Wu SY, Hsieh HP (2005) Novel indole-based peroxisome proliferator-activated receptor agonists: design, SAR, structural biology, and biological activities. J Med Chem 48: 8194-8208. doi:10.1021/ jm0506930.

Mahindroo N, Peng YH, Lin CH, Tan UK, Prakash E, Lien TW, Lu IL, Lee HJ, Hsu JT, Chen X, Liao CC, Lyu PC, Chao YS, Wu SY, Hsieh HP (2006) Structural basis for the structure-activity relationships of peroxisome proliferator-activated receptor agonists. J Med Chem 49: 6421-6424. doi:10.1021/jm060663c.

Mahindroo N, Wang CC, Liao CC, Huang CF, Lu IL, Lien TW, Peng YH, Huang WJ, Lin YT, Hsu MC, Lin CH, Tsai C.H, Hsu JT, Chen X, Lyu PC, Chao YS, Wu SY, Hsieh HP (2006) Indol-1-yl acetic acids as peroxisome proliferator-activated receptor agonists: design, synthesis, structural biology, and molecular docking studies. J Med Chem 49: 1212-1216. doi:10.1021/jm0510373.

Miyamoto S (2002) Recent advances in aldose reductase inhibitors: potential agents for the treatment of diabetic complications. Expert Opin Ther Patents 12: 621-631. doi:10.1517/13543776.12.5.621.

Mylari BL, Armento SJ, Beebe DA, Conn EL, Coutcher JB, Dina MS, O'Gorman MT, Linhares MC, Martin WH, Oates PJ, Tess DA, Withbroe GJ, Zembrowski WJ (2003) A highly selective, non-hydantoin, non-carboxylic acid inhibitor of aldose reductase with potent oral activity in diabetic rat models: 6-(5-chloro-3-methylbenzofuran- 2-sulfonyl)-2-H-pyridazin-3-one. J Med Chem 46: 2283-2286. doi: $10.1021 /$ jm034065z.

Rees-Milton KJ, Jia Z, Green NC, Bhatia M, El-Kabbani O, Flynn TG (1998) Aldehyde Reductase: The Role of C-Terminal Residues in Defining Substrate and Cofactor Specificities. Arch Biochem Biophys 355: 137-144. doi:10.1006/abbi.1998.0721.

Sangster J (1997) In octanol-water partition coefficients: Fundamentals and Physical Chemistry. vol. 2. John Willey \& Sons, England.

Shao Y, Molnar LF, Jung Y, Kussmann J, Ochsenfeld C, Brown ST, Gilbert ATB, Slipchenko LV, Levchenko SV, O’Neill DP, et al (2006) Advances in methods and algorithms in a modern quantum chemistry program package. Phys Chem Chem Phys 8: 3172-3191. doi:10.1039/B517914A.

da Silva FM, dos Santos JC, Campos JL, Mafud AC, Polikarpov I, Figueira AC, Nascimento AS (2013) Structure-based identification of novel PPAR gamma ligands. Bioorg Med Chem Lett 23: 5795-5802. doi:10.1016/j.bmcl.2013.09.010.

Srivastava SK, Ramana KV, Bhatnagar A (2005) Role of aldose reductase and oxidative damage in diabetes and the consequent potential for therapeutic options. Endocr Rev 26: 380-392. doi:http://dx.doi. org/10.1210/er.2004-0028.

Stefek M, Snirc V, Djoubissie PO, Majekova M, Demopoulos V, Rackova L, Bezakova Z, Karasu C, Carbone V, El-Kabbani O (2008) Carboxymethylated pyridoindole antioxidants as aldose reductase inhibitors: Synthesis, activity, partitioning, and molecular modelling. Bioorg Med Chem 16: 4908-4920. doi:10.1016/j.bmc.2008.03.039.

Tang WH, Martin KA, Hwa J (2012) Aldose reductase, oxidative stress, and diabetes mellitus. Frontiers Pharmacol 3: 87. doi:10.3389/ fphar.2012.00087.

Terashima H, Hama K, Yamamoto R, Tsuboshima M, Kikkawa R, Hatanaka I, Shigeta YJ (1984) Effects of a new aldose reductase inhibitor on various tissues in vitro. Pharm Exp Ther 229: 226-230.

Van Zandt MC, Doan B, Sawicki DR, Sredy J, Podjarny AD (2009) Discovery of [3-(4,5,7-trifluoro-benzothiazol-2-ylmethyl)-pyrrolo[2,3b]pyridin-1-yl]acetic acids as highly potent and selective inhibitors of aldose reductase for treatment of chronic diabetic complications. Bioorg Med Chem Lett 19: 2006-2008. doi:10.1016/j.bmcl.2009.02.037.

Van Zandt MC, Jones ML, Gunn DE, Geraci LS, Jones JH, Sawicki DR, Sredy J, Jacot JL, Dicioccio AT, Petrova T, Mitschler A, Podjarny AD (2005) Discovery of 3-[(4,5,7-trifluorobenzothiazol2 -yl)methyl] indole- $\mathrm{N}$-acetic acid (lidorestat) and congeners as highly potent and selective inhibitors of aldose reductase for treatment of chronic diabetic complications. J Med Chem 48: 3141-3152. doi: $10.1021 / \mathrm{jm} 0492094$.

Verheij HJ (2006) Leadlikeness and structural diversity of synthetic screening libraries. Molecular Diversity 10: 377-388. doi:10.1007/ s11030-006-9040-6.

Walker H, Testa B (2009) Drug bioavailability: estimation of solubility, permeability, absorption and bioavailability. WILEY-vch Verlag GmbH \& Co. KGaA Weinheim. doi:10.1002/9783527623860.

Yabe-Nishimura C (1998) Aldose reductase in glucose toxicity: a potential target for the prevention of diabetic complications. Pharm Rev 50: $21-33$. 